\title{
Antidementia Drug Treatment in People Screened Positive for Dementia in Primary Care
}

\author{
Diana Wucherer, ${ }^{\mathrm{a}, *}$, Tilly Eichler ${ }^{\mathrm{a}}$, Ingo Kilimann ${ }^{\mathrm{b}, \mathrm{d}}$, Johannes Hertel ${ }^{\mathrm{a}}$, Bernhard Michalowsky ${ }^{\mathrm{a}}$, \\ Jochen René Thyrian ${ }^{\mathrm{a}}$, Stefan Teipel ${ }^{\mathrm{b}, \mathrm{d}}$ and Wolfgang Hoffmann ${ }^{\mathrm{a}, \mathrm{c}}$ \\ ${ }^{\mathrm{a}}$ German Center for Neurodegenerative Diseases (DZNE), Rostock/Greifswald, Greifswald, Germany \\ ${ }^{\mathrm{b}}$ German Center for Neurodegenerative Diseases (DZNE), Rostock/Greifswald, Rostock, Germany \\ ${ }^{\mathrm{c}}$ Institute for Community Medicine, Section Epidemiology of Health Care and Community Health, University \\ Medicine Greifswald, Greifswald, Germany \\ ${ }^{\mathrm{d}}$ Department of Psychosomatic Medicine, Rostock University Medical Center, Rostock, Germany
}

Accepted 8 October 2014

\begin{abstract}
.
Background: There is a lack of knowledge about antidementia drug treatment in community dwelling people with dementia in Germany.

Objective: To determine the frequency of treatment with antidementia drugs in patients in primary care, and the sociodemographic and clinical variables associated with antidementia drug treatment.

Methods: Present analyses are based on preliminary data from the DelpHi-trial, an ongoing GP-based, cluster-randomized, controlled intervention trial to implement and evaluate an innovative concept of collaborative dementia care management in Germany. Our sample consists of $n=243$ subjects who screened positive for dementia.

Results: $29.6 \%(n=72)$ of participants received antidementia drugs: memantine $44.5 \%(n=32)$; donepezil $30.5 \%(n=22)$; rivastigmine $13.9 \%(n=10)$; galantamine $11.1 \%(n=8)$. A total of $46.4 \%(n=45)$ of the subgroup of participants with a formal dementia diagnosis received antidementia drug treatment. Approximately $37.5 \%(n=27)$ of our sample received treatment with antidementia drugs without having a formal diagnosis. Treatment with antidementia drugs was significantly associated with more severe cognitive impairment and having a formal dementia diagnosis.

Conclusions: One in three people who screened positive for dementia in primary care received antidementia drug treatment, indicating the frequent use of this class of drugs. For those with a formal dementia diagnosis, these drug treatment rates are more than triple, compared to those in nursing homes.
\end{abstract}

Keywords: DelpHi-MV trial, dementia, donepezil, galantamine, memantine, primary health care, rivastigmine

ClinicalTrials.gov Identifier: NCT01401582

\section{INTRODUCTION}

The treatment and care of people with dementia (PWD) is a major challenge in aging societies. In accordance with international guidelines [1], the German national guidelines recommend antidementia drug

\footnotetext{
*Correspondence to: Diana Wucherer, German Center for Neurodegenerative Diseases (DZNE), Rostock/Greifswald, Ellernholzstrasse 1-2, Greifswald D-17487, Germany. Tel.: +49383486 7776; Fax: +49 383486 19551; E-mail: diana.wucherer@dzne.de.
}

treatment primarily for Alzheimer's disease (AD) [2, $3]$. AD is currently incurable, and primarily the palliative approaches of the pharmacotherapy are discussed in the guidelines. The guidelines recommend acetylcholinesterase inhibitors donepezil, galantamine, and rivastigmine for the treatment of mild to moderate $\mathrm{AD}$, and memantine for the treatment of moderate to severe $\mathrm{AD}$. Oral rivastigmine is recommended for the treatment of dementia in Parkinson's disease. There is presently no specific recommendation for the treatment 
of Lewy body, vascular, and frontotemporal dementia $[2,3]$. The individual risk-benefit trade-offs the severity of the disease and the will of patients and their caregivers are to be considered in the treatment decisions [2-4].

Grass-Kapanke et al. showed that $55 \%$ of 2,000 community-dwelling subjects with dementia who received ambulatory nursing care received no antidementia drug therapy according to their formal caregivers [5]. Assuming a prevalence of at least $70 \%$ $\mathrm{AD}$ cases in people with dementia at age 65 and higher, this finding indicates that a large proportion of $\mathrm{AD}$ cases does not receive treatment with antidementia drugs. Van den Bussche et al. analyzed the claims data of in the ambulatory medical care setting in Germany and found a prescription rate (within one year after the diagnosis) of $19 \%$ (acetylcholinesterase inhibitors and memantine) [6]. According to the claims data, only $15 \%$ of nursing home residents with formally diagnosed dementia in Germany are treated with antidementia drugs [7]. Studies using primary data reported an even smaller percentage $(13 \%)$ in Norway [8]. This may indicate a lack of guidelines for the recommended drug treatment of nursing home residents. However, the data vary between countries and data sources. Studies using health insurance claims data reported that $54 \%$ of nursing home residents with dementia in France [9] and 40\% in the United States [10] received acetylcholinesterase inhibitors or memantine. Primary data on the prevalence of antidementia drug treatment in community dwelling PWD in Germany is lacking. The formal diagnosis is an inclusion criterion for antidementia drug treatment analyses in claims data, and consequently, a considerable proportion of people with dementia are excluded in secondary data analyses because a majority of PWD are not formally diagnosed with dementia [11-14]. Therefore, the main objectives of the present study were to analyze: (1) the frequency and type of antidementia drug treatment in German primary care patients, and (2) the socio-demographic and clinical variables associated with antidementia drug treatment in these subjects.

\section{MATERIALS AND METHODS}

\section{Study design}

The present analysis is based on data from the DelpHi-MV study (Dementia: life- and personcentered help in Mecklenburg-Western Pomerania). This is an ongoing, general practitioner (GP)-based cluster-randomized controlled intervention trial to implement and evaluate an innovative concept of collaborative dementia care management in Germany that started in January, 2012 [15, 16]. In general practices, patients of 70 years of age or older living at home are screened for dementia. To be eligible for participation in the DelpHi-MV-study, patients need to be screened as positive for dementia (DemTect $<9$ ) and to provide written informed consent.

A caregiver, whose name is provided by the patient, is kindly requested to participate in the study. In the case a patient is unable to give written informed consent, the informed consent form is signed by his or her legal representative (as approved by the Ethical Committee of the Chamber of Physicians of Mecklenburg-Western Pomerania, registry number BB 20/11). All participants participate in a comprehensive standardized baseline assessment delegated to the Dementia Care Manager, specially qualified study nurses $[15,17,18]$, at the persons' homes.

\section{Participants}

Of the 4,064 patients ( $\geq 70$ years of age, living at home), screened for dementia in 108 participating GP practices, 629 patients $(17 \%)$ were eligible for the DelpHi-trial (DemTect $<9$ ), and of these, 406 patients (59\%) agreed to participate. The present analyses are based on the data from 243 patients with complete baseline assessments regarding relevant variables on January 1, 2014 (preliminary data). Some 90 participants had not finished the baseline assessment at the time of the analysis, and 58 patients dropped out of the study due to the withdrawal of informed consent $(n=31)$; death $(n=20)$; relocation $(n=3)$; or other reasons $(n=4)$. There were no significant differences between the patients who were included and those who were dropped regarding the DemTect score, age, and gender (see Supplementary Table 1).

Fifteen patients were excluded because the instruments could not be utilized (patients were either not able to answer the questions due to the severity of dementia or patients refused to answer because of other reasons). Patients included in the analysis showed significantly higher DemTect scores $(\mathrm{M}=5.84, \mathrm{SD}=2.02)$ than patients who were excluded because of missing data $(\mathrm{M}=3.73, \mathrm{SD}=2.34$; Welch's$t$-test: $\mathrm{t}(15.50)=3.41 ; p<0.01)$ and used antidementia drugs more often (Fishers exact Test, $p<0.01$ ). No significant differences were observed for the variables age, gender, and formal diagnosis of dementia (see Supplementary Table 2). 


\section{Data assessment and analyses}

We assessed the variables age, gender, living situation (alone/not alone), cognitive status, medical diagnoses, depression, functional status, and medication. The severity of cognitive impairment was assessed using the Mini-Mental State Examination (MMSE) [19]. The severity of dementia was categorized as: "no cognitive impairment" (score 27-30), "mild" (20-26), "moderate" (10-19), or "severe cognitive impairment" (0-9) [3]. Depression was assessed using the Geriatric Depression Scale and categorized as "no depression" (score 0-5) or "depression" (score 6-15) [20]. Functional status was assessed using the Bayer Activities of Daily Living Scale (B-ADL) [21, 22], which yields a mean score between 1 and 10 , where 1 indicates the lowest and 10 indicates the highest possible impairment. In accordance with the International Statistical Classification of Diseases and Related Health Problems (ICD-10, German Modification) [23], the medical diagnoses of dementia were retrieved from the medical records of the treating GP, including the exact date of the initial diagnosis. Dementia diagnoses assigned on the screening day or thereafter were excluded from these analyses. The ICD-10 codes considered were: F00/G30 (dementia due to AD), F01 (vascular dementia), F02 (dementia in other diseases), F03 (unspecified dementia), and G31 (other degenerative diseases of nervous system, not otherwise classified).

A computer-based home medication review [15, 17, 18] encompasses all medications used by the study participants and includes questions about compliance, adverse effects and drug administration. The collection of primary data on medication in the context of the home medication review includes both prescription drugs and over-the-counter drugs. The assignment was then integrated using a master file of the Pharmaceutical Index [24]. The following antidementia drugs were considered: donepezil (N06AD02), rivastigmine (N06AD03), galantamine (N06AD04), and memantine (N06AX01).

The variables describing the sample were summarized using descriptive statistics. We fitted a logistic regression model to determine which variables are associated with the antidementia drug treatment. The regression model includes cognitive status (measured with MMSE) as an explanatory variable and age, gender, living situation, depression, functional status (measured with B-ADL), visit to a specialist (psychiatrists/neurologists) and diagnosis of dementia as covariates to evaluate the association between cogni- tive status and antidementia drug treatment. To account for the dependency of data from participants that belong to the same cluster (i.e., treating GP), we applied a conditional (fixed effect) logistic regression model, which offers consistent estimates in the case of clustered data. Before running the final regression model, we checked for non-linear relationships using the multivariate fractional polynomial procedure, and no indication of non-linearity was found. A total of 44 observations were excluded from the estimation procedure because of the invariance in the outcome-variables in the respective clusters (i.e., all or none of the patients treated by the same GP take antidementia medication). We found no significant differences between the included and excluded cases regarding the covariates analyzed (see Supplementary Table 3), but the frequency of antidementia drug use differed significantly between these groups. This fact is discussed below. The final regression analysis was performed with the remaining $n=199$ cases belonging to $n=30$ clusters (clusters are unbalanced). The standard errors of the regression coefficients were estimated with the Jackknife method, which provides appropriate estimates of standard errors in complex samples. Statistical analyses were performed with STATA ${ }^{\circledR} 11$ [25].

\section{RESULTS}

\section{Socio-demographic and clinical characteristics}

The sociodemographic and clinical characteristics of the study population are summarized in Table 1.

\section{Antidementia drug treatment}

Of 243 community-dwelling people who screened positive for dementia, a total of $n=72$ (29.6\%) received antidementia drugs. The most frequently prescribed medications for people receiving antidementia drugs were memantine $(n=32 ; 44.5 \%)$, followed by donepezil $(n=22 ; 30.5 \%)$, rivastigmine $(n=10$;

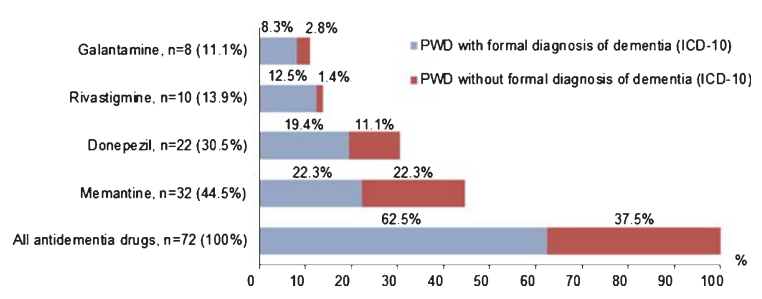

Fig. 1. Antidementia drug treatment in study participants with and without formally diagnosed dementia $(n=72)$. 
$13.9 \%)$, and galantamine ( $n=8 ; 11.1 \%)$ (Fig. 1). No cases of combination therapy with acetylcholinesterase inhibitors and memantine were found. In the group of participants receiving antidementia drug treatment, $62.5 \%(n=45)$ had a formal diagnosis of dementia, leaving $37.5 \%(n=27)$ being treated without a formal diagnosis. In the subgroup of study participants with a formal diagnosis of dementia, $46.4 \%(n=45)$ received antidementia medication. Additional details are given in Table 1.

The analysis of antidementia drug use and specific dementia diagnosis showed that $64.7 \%(n=11)$ of the patients with an $\mathrm{AD}$ diagnosis, $43.5 \%(n=10)$ of the patients with a vascular dementia diagnosis and $47.0 \%$ $(n=31)$ of the patients with an unspecified dementia diagnosis were treated with antidementia drugs (note that 14 patients have more than one dementia diagno- sis, retrieved from the medical records of the treating GP, double entries are therefore possible) (Table 2).

\section{Factors associated with the antidementia drug treatment}

The results of the multivariate conditional logistic regression analysis (significant model, $p=0.004$ ) are shown in Table 3. The prescription for antidementia drugs was significantly associated with the severity of cognitive impairment (mean MMSE score: 19.2 versus 23.1, OR, 0.84; $p=0.010$ ) and a formal dementia diagnosis (OR, 2.79; $p=0.034)$. Each additional point in the MMSE score corresponded to an $18 \%$ lesser chance of receiving an antidementia drug $(\mathrm{OR}=0.84 ; p=0.010)$. Patients who received a formal diagnosis of dementia had approximately a $180 \%$ higher chance of receiving

Table 1

Sociodemographic and clinical characteristics of the study sample

\begin{tabular}{|c|c|c|c|c|}
\hline & \multicolumn{2}{|c|}{ Study participants } & \multirow{2}{*}{$\begin{array}{c}\text { Total } \\
n=243\end{array}$} & \multirow[t]{2}{*}{$p$-value } \\
\hline & $\begin{array}{l}\text { With antidementia drug } \\
\text { treatment }(n=72)\end{array}$ & $\begin{array}{c}\text { Without antidementia drug } \\
\text { treatment }(n=171)\end{array}$ & & \\
\hline \multicolumn{5}{|l|}{ Gender } \\
\hline Male & $28(29.5 \%)$ & $67(70.5 \%)$ & $95(39 \%)$ & \\
\hline Female & $44(29.7 \%)$ & $104(70.3 \%)$ & $148(61 \%)$ & $1.000^{\mathrm{a}}$ \\
\hline Age: mean years & $79.0(\mathrm{SD} 5.31)$ & 79.9 (SD 5.49) & $79.6(\mathrm{SD} 5.44)$ & $0.261^{\mathrm{b}}$ \\
\hline \multicolumn{5}{|l|}{ Living situation } \\
\hline Alone & $38(29.2 \%)$ & $92(70.8 \%)$ & $130(53.5 \%)$ & \\
\hline Not alone & $34(30.1 \%)$ & $79(69.9 \%)$ & $113(46.5 \%)$ & $0.889^{\mathrm{a}}$ \\
\hline Cognitive impairment (MMSE): mean score & $19.4(\mathrm{SD} 6.20)$ & $23.1(\mathrm{SD} 4.78)$ & $22.0(\mathrm{SD} 5.50)$ & $0.001^{\mathrm{b}}$ \\
\hline no cognitive impairment (score, 27-30) & $9(15.5 \%)$ & $49(84.5 \%)$ & $58(23.9 \%)$ & \\
\hline mild (score, 20-26) & $26(24.5 \%)$ & $80(75.5 \%)$ & $106(43.6 \%)$ & \\
\hline moderate (score, 10-19) & $29(43.9 \%)$ & $37(56.1 \%)$ & $66(27.2 \%)$ & \\
\hline severe cognitive impairment (score, $0-9$ ) & $8(61.5 \%)$ & $5(38.5 \%)$ & $13(5.3 \%)$ & $0.001^{\mathrm{a}}$ \\
\hline With dementia diagnosis ${ }^{1}$ & $45(46.4 \%)$ & $52(53.6 \%)$ & $97(39.9 \%)$ & \\
\hline Without dementia diagnosis & $27(18.5 \%)$ & $119(81.5 \%)$ & $146(60.0 \%)$ & $0.001^{\mathrm{a}}$ \\
\hline
\end{tabular}

Standard deviations or percentages are in brackets. MMSE, Mini-Mental State Examination, range 0-30, higher score indicates better cognitive functioning; ${ }^{1}$ at least one diagnosis. ${ }^{a}$ Fisher's exact test ${ }^{\text {b}}$ Welch $t$-test.

Table 2

Antidementia drug treatment in study participants with formally diagnosed dementia $(n=97)$

\begin{tabular}{|c|c|c|c|c|c|}
\hline & \multicolumn{5}{|c|}{ Antidementia drugs } \\
\hline & \multirow{2}{*}{$\begin{array}{c}\text { NMDA-antagonist } \\
\text { Memantine } \\
n=32\end{array}$} & \multicolumn{3}{|c|}{ Acetylcholinesterase inhibitors } & \multirow{2}{*}{$\begin{array}{l}\text { Total } \\
(n=45)\end{array}$} \\
\hline & & $\begin{array}{c}\text { Donepezil } \\
n=22\end{array}$ & $\begin{array}{c}\text { Rivastigmine } \\
n=10\end{array}$ & $\begin{array}{c}\text { Galantamine } \\
n=8\end{array}$ & \\
\hline Dementia diagnosis $^{1}$ (F00-F03, G30-G31), $n=97$ & 16 & 14 & 9 & 6 & 45 \\
\hline F00/G30: Dementia in Alzheimer's disease, $n=17$ & 4 & 5 & 1 & 1 & 11 \\
\hline F01: Vascular dementia, $n=23$ & 4 & 3 & 1 & 2 & 10 \\
\hline F02: Dementia in other diseases, $n=1$ & - & - & 1 & - & 1 \\
\hline F03: Unspecified dementia, $n=66$ & 11 & 9 & 7 & 4 & 31 \\
\hline $\begin{array}{l}\text { G31: Other degenerative diseases of } \\
\text { nervous system, not elsewhere classified, } n=4\end{array}$ & 1 & 1 & - & - & 2 \\
\hline
\end{tabular}

\footnotetext{
1 at least one diagnosis, double entries possible.
} 
Table 3

Factors associated with antidementia drug treatment

\begin{tabular}{|c|c|c|c|c|c|c|}
\hline & \multicolumn{2}{|c|}{ Study participants } & \multirow[t]{2}{*}{ OR } & \multirow[t]{2}{*}{$p$} & \multirow[t]{2}{*}{$95 \% \mathrm{CI}$} & \\
\hline & No antidementia drugs $(n=134)$ & Antidementia drugs $(n=65)$ & & & & \\
\hline Age & 79.9 (SD 5.5) & $79.0($ SD 5.3) & 0.97 & 0.519 & 0.89 & 1.06 \\
\hline Gender (female) & $83(62 \%)$ & $41(63 \%)$ & 1.21 & 0.735 & 0.39 & 3.74 \\
\hline Cognitive impairment (MMSE) & 23.1 (SD 4.9) & $19.2(\mathrm{SD} 6.18)$ & 0.84 & 0.01 & 0.75 & 0.96 \\
\hline Depression (GDS $\geq 6$ ) & $20(15 \%)$ & $12(18 \%)$ & 0.94 & 0.919 & 0.28 & 3.17 \\
\hline Functional status (B-ADL) & $3.3(\mathrm{SD} 2.3)$ & $4.2(\mathrm{SD} 6.18)$ & 0.94 & 0.632 & 0.71 & 1.23 \\
\hline Living alone & $74(55 \%)$ & $34(52 \%)$ & 0.86 & 0.738 & 0.34 & 2.17 \\
\hline Visit to neurologist/psychiatrist & $30(22 \%)$ & $28(43 \%)$ & 2.05 & 0.19 & 0.69 & 6.03 \\
\hline With dementia diagnosis & $40(30 \%)$ & $35(54 \%)$ & 2.79 & 0.034 & 1.08 & 7.19 \\
\hline
\end{tabular}

Conditional fixed effect logistic regression analysis (with $n=199$ patients assigned to $n=30$ clusters): $p=0.004$; Standard deviations or percentages are in brackets. OR, odds ratio; CI, confidence interval; MMSE, Mini-Mental State Examination, range 0-30, higher score indicates better cognitive functioning; B-ADL, Bayer Activities of Daily Living Scale, range 0-10, lower score indicates better performance; GDS, Geriatric Depression Scale, sum score 0-15, score $\geq 6$ indicates depression; Dementia diagnosis: at least one ICD-diagnosis (F00-F03, G30-G31).

antidementia drug treatment, compared to people with no diagnosis of dementia $(\mathrm{OR}=2.79 ; p=0.034)$.

\section{DISCUSSION}

\section{Antidementia drug treatment}

Approximately $30 \%$ of primary care patients who screened positive for dementia received specific antidementia drug treatment, with the most frequently prescribed antidementia agents being memantine and the acetylcholinesterase inhibitor donepezil. Due to the lack of comparable data (as previously stated, most studies used a formal diagnosis as inclusion criteria), we cannot estimate whether this is a high or low rate. In general, a formal diagnosis is important for adequate treatment and care [14]. However, due to our finding that people without formal diagnosis are treated with antidementia drugs, it is necessary to consider our results on primary care studies on antidementia drug treatment. Our findings support that $43 \%$ of people receiving antidementia drug treatment have received specialist treatment (neurologist/psychiatrist), according to their own disclosures. However, our data do not deliver information about the relation between formal diagnosis and drug treatment. The question remains open: were the antidementia drugs prescribed by GPs without a dementia diagnosis? Were the antidementia drugs prescribed by the specialists, but the diagnoses were not registered by the GP in medical records? Not only cases matching with the diagnosis must be considered in the analysis of antidementia drugs, but also the cases without formal diagnosis.

For people with a formal dementia diagnosis in primary care, almost half receive antidementia drug treatment. This finding is comparable to the prevalence of antidementia drug utilization in nursing service-supplied outpatients in Germany (45\%) [5]. In comparison to nursing home residents, the rate of antidementia drug treatment was considerable higher (15\%) [7]. One explanation could be that there is a high proportion (approximately $60 \%$ ) of residents with severe dementia in nursing homes [26] where therapy with antidementia drugs has been terminated already. A possible reason for this effect is the multimorbidity of nursing home residents and the associated polypharmacy. The risk of adverse drug interactions or side effects increases with the number of different drugs and may cause non-adherence with the antidementia drug treatment. However, the low rate of antidementia drug treatment likely implies a certain degree of under-treatment of PWD in nursing homes.

The highest frequency of antidementia drug taking was observed in the group of participants with $\mathrm{AD}$ diagnosis $(65 \%)$, which also corresponds to the recommendations of the guidelines. In our analysis this observed frequency is higher than in the comparable analyses with the secondary data. Van den Bussche et al. also found in their analysis of claims data, that the prescription rate for guideline-conform drugs was higher in patients diagnosed with $\mathrm{AD}(35 \%$ within one year after the diagnosis) [6].

In the present analysis, we found that less than half of the patients with the diagnosis of unspecified dementia received antidementia drugs $(47 \%)$. That finding is interesting, because the use of anti-dementia drugs for unspecified dementia is an off-label treatment, and the difficulty of treatment should be adequately considered. AD is the most common type of dementia and accounts for an estimated $60 \%$ to $80 \%$ of all cases [27]. 
We suspect that a majority of the people with dementia who had been diagnosed with unspecified dementia in our analysis could in fact have AD. Although AD is the most recognized form of dementia, the other types have distinct clinical features and are often overlooked [28]. Earlier differential diagnosis provides access to a pathway of evidence-based treatment, care and support across the disease course [12] and should be implemented.

We suppose that in addition to doubts about the effectiveness of antidementia drugs on the part of physicians, the costs of antidementia drugs may be relevant to the prescription of the antidementia drugs [4, 29-31].

\section{Factors associated with antidementia drug treatment}

Antidementia drug treatment is significantly associated with more severe cognitive impairment and the presence of a formal diagnosis of dementia. This is in line with the current guidelines. An interesting question, however, is whether different types of diagnosis are associated in multivariate analysis with different prescription rates reflecting the above mentioned descriptive differences. However, in this study, casenumbers for subtypes of dementia were too small to conduct adequate cluster-adjusted inferential statistical analysis.

Our results do not indicate that the visit to a neurologist or psychiatrist is associated with antidementia drug treatment. This finding is only partially consistent with previous studies. Hoffmann et al. found that contact with specialists is strongly associated with acetylcholinesterase inhibitor prescriptions [32] and van den Bussche describes that specialists prescribe antidementia drugs twice often as GPs [6]. We suspect that the insufficient number of cases in our study is the reason why our results are inconsistent with others.

\section{Limitations}

The size of the sample was not sufficient to allow for meaningful subgroup analysis regarding patients with the diagnoses F02 (Dementia in other diseases; $n=1$ ) and G31 (other degenerative diseases of nervous system, not elsewhere classified; $n=4)$.

In the 44 observations excluded from the logistic regression model, the prevalence of antidementia drug use was lower compared to the observations included in the model (16\% versus $33 \%)$. These are the patients of those general physicians who generally prescribe the antidementia drugs either for all or for none of their patients with dementia. This could restrict the transferability of the logistic regression results.

\section{Summary}

As far as we are aware, our present analysis is the first to analyze primary data of antidementia drug treatment in community dwelling primary care patients in Germany who screened positive for dementia. The effort of primary data collection pays off in terms of the high quality of the data: the rate of antidementia drug treatment in primary care is relevant, and there is considerable number of people treated with antidementia drugs without having a formal diagnosis. In patients with formally diagnosed dementia, antidementia drug treatment was much more frequent compared with PWD in German nursing homes. Complying with treatment guidelines, study participants with a diagnosis of $\mathrm{AD}$ showed the highest prevalence of antidementia drug treatment $(64.7 \%)$. There is more than half (53.6\%) formally diagnosed PWD who do not receive any antidementia drug treatment. Antidementia drug treatment should be based on an individual assessment of risks and benefits. GPs should be informed about the benefits and risks of pharmacotherapy for patients with dementia. Likewise, education about options and criteria for antidementia drug treatment should be offered to PWD and their caregivers.

\section{ACKNOWLEDGMENTS}

We would like to express appreciation to all study participants and their general practitioners for their cooperation. We also would like to thank the several experts who contributed to the development of the study. These are (in alphabetical order): Ines Abraham, Kerstin Albuerne, Aniela Angelow, Grit Assmann, Vaska Böhmann, Georgia Böwing, Kathleen Dittmer, Thomas Fiß, Daniel Fredrich, Sarah Gardzella, Jana Hubert, Ulrike Kempe, Saskia Moll, Sabine Schmidt, Christiane Schnick, Christine Winckler, Paula Winter.

Authors' disclosures available online (http://www.jalz.com/disclosures/view.php?id=2590).

\section{SUPPLEMENTARY MATERIAL}

The supplementary material is available in the electronic version of this article: http://dx.doi.org/10.3233/ JAD-142064. 


\section{REFERENCES}

[1] Hort J, O’Brien JT, Gainotti G, Pirttila T, Popescu BO, Rektorova I, Sorbi S, Scheltens P (2010) EFNS guidelines for the diagnosis and management of Alzheimer's disease. Eur J Neurol 17, 1236-1248.

[2] Deutsche Gesellschaft für Allgemeinmedizin und Familienmedizin e.V. (DEGAM), DEGAM-Leitlinie Nr 12: Demenz, omikron publishing, Düsseldorf, (2008).

[3] Deutsche Gesellschaft für Psychiatrie, Psychotherapie und Nervenheilkunde und Deutsche Gesellschaft für Neurologie (DGN) (2009) S-3 Leitlinie "Demenzen". http://www. dgppn.de/fileadmin/user_upload/_medien/download/pdf/kurz version-leitlinien/s3-leitlinie-demenz-lf.pdf

[4] Casey DA, Antimisiaris D, O'Brien J (2010) Drugs for Alzheimer's disease: Are they effective? P T 35, 208-211.

[5] Grass-Kapanke B, Kunczik T, Gutzmann H (2014) Studie zur Demenzversorgung im ambulanten Sektor- DIAS . Schriftenreihe der Deutschen Gesellschaft für Gerontopsychiatrie und - psychotherapie e V Band 7.

[6] van den Bussche H, Kaduszkiewicz H, Koller D, Eisele M, Steinmann S, Glaeske G, Wiese B (2011) Antidementia drug prescription sources and patterns after the diagnosis of dementia in Germany: Results of a claims data-based 1-year follow-up. Int Clin Psychopharmacol 26, 225-231.

[7] Huber M, Kolzsch M, Rapp MA, Wulff I, Kalinowski S, Bolbrinker J, Hofmann W, Scholze J, Drager D, Kreutz R (2012) Antipsychotic drugs predominate in pharmacotherapy of nursing home residents with dementia. Pharmacopsychiatry 45, 182-188.

[8] Kruger K, Folkestad M, Geitung JT, Eide GE, Grimsmo A (2012) Psychoactive drugs in seven nursing homes. Prim Health Care Res Dev 13, 244-254.

[9] Rolland Y, Andrieu S, Crochard A, Goni S, Hein C, Vellas B (2012) Psychotropic drug consumption at admission and discharge of nursing home residents. J Am Med Dir Assoc 13, 407-412.

[10] Parsons C, Briesacher BA, Givens JL, Chen Y, Tjia J (2011) Cholinesterase inhibitor and memantine use in newly admitted nursing home residents with dementia. J Am Geriatr Soc 59, 1253-1259.

[11] Mitchell AJ, Meader N, Pentzek M (2011) Clinical recognition of dementia and cognitive impairment in primary care: A meta-analysis of physician accuracy. Acta Psychiatr Scand 124, 165-183.

[12] Prince M, Bryce R, Ferri C. (2011) World Alzheimer Report 2011: The benefits of early diagnosis and intervention. Alzheimer's Disease International (ADI), London, UK.

[13] Boustani M, Callahan CM, Unverzagt FW, Austrom MG, Perkins AJ, Fultz BA, Hui SL, Hendrie HC (2005) Implementing a screening and diagnosis program for dementia in primary care. J Gen Intern Med 20, 572-577.

[14] Eichler T, Thyrian J, Hertel J, Köhler L, Wucherer D, Dreier A, Michalowsky B, Teipel S, Hoffmann W (2014) Rates of formal diagnosis in people screened positive for dementia in primary care: Results of the DelpHi-Trial. J Alzheimers Dis 42, 451-458.

[15] Eichler T, Thyrian JR, Dreier A, Wucherer D, Kohler L, Fiss T, Bowing G, Michalowsky B, Hoffmann W (2014) Dementia care management: Going new ways in ambulant dementia care within a GP-based randomized controlled intervention trial. Int Psychogeriatr 26, 247-256.

[16] Thyrian JR, Fiss T, Dreier A, Bowing G, Angelow A, Lueke S, Teipel S, Flessa S, Grabe HJ, Freyberger HJ, Hoffmann W (2012) Life- and person-centred help in MecklenburgWestern Pomerania, Germany (DelpHi): Study protocol for a randomised controlled trial. Trial 13, 56.

[17] Fiss T, Thyrian JR, Wucherer D, Assmann G, Kilimann I, Teipel SJ, Hoffmann W (2013) Medication management for people with dementia in primary care: Description of implementation in the DelpHi study. BMC Geriat 13, 121.

[18] Dreier A, Hoffman W (2013) Dementia Care Manager für Patienten mit Demenz. Bundesgesundheitsblatt Gesundheitsforschung Gesundheitsschutz 56, 1398-1409.

[19] Kessler J, Markowitsch HJ, Denzler P. (1990) Mini-MentalStatus-Test (MMST). [German Version].

[20] Gauggel S, Birkner B (1999) Validity and reliability of a German version of the Geriatric Depression Scale (GDS). Zeitschrift Klinische Psychologie-Forschung Praxis 28, 1827.

[21] Erzigkeit H, Lehfeld H, Pena-Casanova J, Bieber F, YekrangiHartmann C, Rupp M, Rappard F, Arnold K, Hindmarch I (2001) The Bayer-Activities of Daily Living Scale (B-ADL): Results from a validation study in three European countries. Dement Geriatr Cogn Disord 12, 348-358.

[22] Hindmarch I, Lehfeld H, de JP, Erzigkeit H (1998) The Bayer Activities of Daily Living Scale (B-ADL). Dement Geriatr Cogn Disord 9(Suppl 2), 20-26.

[23] Deutsches Institut für medizinische Dokumentation und Information (DIMDI) (2013) ICD-10-GM. http://www. dimdi.de/static/de/klassi/icd-10-gm/index.htm.

[24] WJdo (2013) ATC/DDDR-Rom 2013 Anatomischtherapeutisch-chemische Klassifikation mit Tagesdosen für den deutschen Arzneimittelmarkt. GKV-Arzneimittelindex.

[25] StataCorp. (2009) Stata Statistical Software: Release 11.

[26] Makai P, Beckebans F, van EJ, Brouwer WB (2014) Quality of life of nursing home residents with dementia: Validation of the German version of the ICECAP-O. PLos One 9, e92016.

[27] Alzheimer's, Association (2013) 2013 Alzheimer's disease facts and figures. Alzheimers Dement 9, 208-245.

[28] Ronan M, Factora M, Babak Tousi M (2014) Don't forget non-Alzheimer dementias. Cleve Clin J Med 81, 243-254.

[29] Kiencke P, Daniel D, Grimm C, Rychlik R (2011) Direct costs of Alzheimer's disease in Germany. Eur J Health Econ 12, 533-539.

[30] Michalowsky B, Eichler T, Thyrian JR, Hertel J, Wucherer D, Laufs S, Fleßa S, Hoffmann W (2014) Medication cost of persons with dementia in primary care in Germany. J Alzheimers Dis 42, 949-958.

[31] Melchinger H (2007) Demenzerkrankungen. Chronische Versorgungsdefizite. DtArztebl 104, A3236-A3237.

[32] Hoffmann F, van den Bussche H, Wiese B, Schon G, Koller D, Eisele M, Glaeske G, Scherer M, Kaduszkiewicz H (2011) Impact of geriatric comorbidity and polypharmacy on cholinesterase inhibitors prescribing in dementia. $B M C$ Psychiatr 11, 190. 